\title{
Maximum Power Point Tracker for Photovoltaic Systems using On-line Learning Neural Networks
}

\author{
Mohamed Tahar Makhloufi \\ PG Scholar \\ Electronics Engineering Dept. \\ University of Batna, Algeria.
}

\author{
Yassine Abdessemed \\ Associate Professor \\ Electronics Engineering Dept. \\ University of Batna, Algeria.
}

\author{
Mohamed Salah Khireddine \\ Associate Professor \\ Electronics Engineering Dept. \\ University of Batna, Algeria.
}

\begin{abstract}
In this paper a new maximum-power-point-tracking (MPPT) controller for a photovoltaic (PV) energy conversion system is proposed. Nowadays, PV generation is more and more used as a renewable energy source. However, its main drawback is that PV generation is intermittent because it depends on shading conditions consequently irradiance value. Thus, the MPPT (Maximum Power Point Tracking Technique) together with the battery energy storage is necessary in order to obtain a stable and reliable maximum output power from a PV generation system.

In our research work, the reference voltage for the MPPT is obtained by an artificial neural network (ANN) using the steepest negative gradient algorithm. The tracking algorithm adjusts the duty-cycle value of the $\mathrm{dc} / \mathrm{dc}$ buck converter so that the PV-module voltage equals the voltage corresponding to the MPPT for any given realistic operation irradiance and temperature.

The controller, which uses the classical perturb and observe $(\mathrm{P} \& \mathrm{O})$ technique processes then the information gathered to a ANN controller bloc, which in turn generates the optimal value of the buck converter duty-cycle. The energy obtained from the converter is stored in a lithium-ion battery which feeds a useful load. The simulation results show the effectiveness of this method for the extraction of the maximum power available in the presence of different types of disturbances.
\end{abstract}

\section{General Terms}

Solar Energy, Photovoltaic Panel, Maximum Output Power, Impedance Matching, Battery charge/discharge, Artificial Intelligence, Controller.

Keywords - Photovoltaic, MPPT, Impedance Matching, DC/DC converter, Lithium-ion battery, Perturb and Observe (P\&O) algorithm, SOC, Artificial Neural Network Controller.

\section{INTRODUCTION}

Photovoltaic (PV) sources are used nowadays in many applications such as battery charging, water pumping, satellite power systems, etc.... For the best system utilization, the photovoltaic cells must operate at their maximum power point (MPP) [1] The maximum power point tracking technique (MPPT) is used in photovoltaic (PV) systems to maximize the photovoltaic array output power, irrespective of the temperature and irradiation conditions and of the load electrical characteristics [1]-[2], and [3].Figures 1 and 2 shows the variation of typical PV module power-voltage characteristics as a function of irradiation and temperature. It can be observed that the temperature changes mainly have an impact on the PV output voltage, while the irradiation changes mainly have an impact on the PV output power.

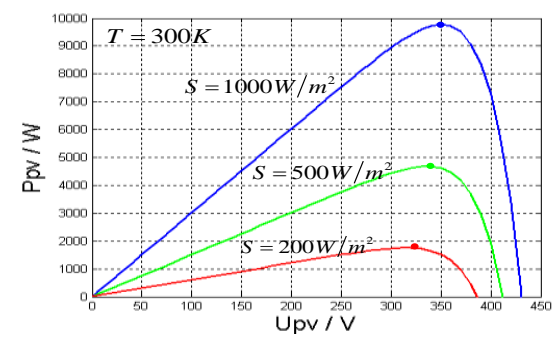

Fig 1: Variation of the PV output power with solar irradiance

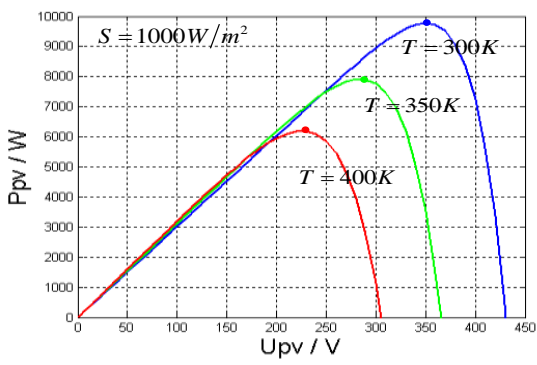

Fig 2: Variation of the PV output power with ambient temperature

Consequently, PV systems should be designed for operating at their maximum output power levels for any temperature and solar irradiation values.

Generally, if the load is directly coupled with the solar array panel, the operating point does not coincide with the maximum power point. To fulfill the load demand, direct connection of the load to the solar array leads to over sizing the solar panels thus increases the cost of the entire system. To solve the problem, a DC/DC converter with an automatic duty cycle control is usually inserted between the solar panel and the load [3]-[4] and [5]. The MPPT computing system modifies the duty cycle of the main converter switch and implicitly the input impedance of the converter until the system reaches the maximum power point. The algorithms commonly used to track the MPPT are the P\&O method has been widely used because it is easy to implement.

There are many techniques to adapt the load impedance value in order to obtain the optimal solar panel output voltage [6][7] and [8]. A general diagram is presented in figure 3 which consists of an MPPT computing system and a DC/DC converter. The DC/DC converter acts as an impedance matching unit. The MPPT computing system measures the 
input voltage and the input current and computes the power in order to control the DC/DC converter. The storage device can be either a battery or a super capacitor [7]

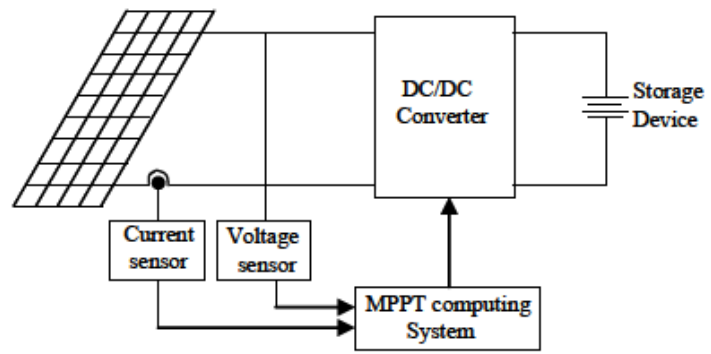

Fig 3: The solar power PV system

The tracking algorithm changes the duty ratio of the converter so that the PV module voltage equals the voltage corresponding to the MPP at the atmospheric working condition. Some techniques use classical PI controllers to adjust the duty cycle [8] or intelligent regulators [9] based on fuzzy logic, neural networks or both.

However in our present research work, we implement an efficient adjustment of the duty cycle using an artificial neural network strategy based on a MLP where a back-propagation algorithm is carried out for optimizing the output power and to insure robustness during considerable perturbations. The reference voltage to the MPP is obtained using the on-line trained ANN. The controller generates in all working conditions the optimal buck converter duty-cycle.

\section{CHARACTERISTICS OF A SOLAR MODULE.}

The solar array characteristics significantly influence the design of the converter and the control system, so the PV characteristics will be briefly reviewed here. Photovoltaic cell is the most basic generation part in PV system. Single diode mathematic model [5] is applicable to simulate silicon photovoltaic cells, which consists of a photo current source, $I_{p h}$, a nonlinear diode, the internal resistances $R_{S}$ and $R_{c h}$, as shown in figure 4 .

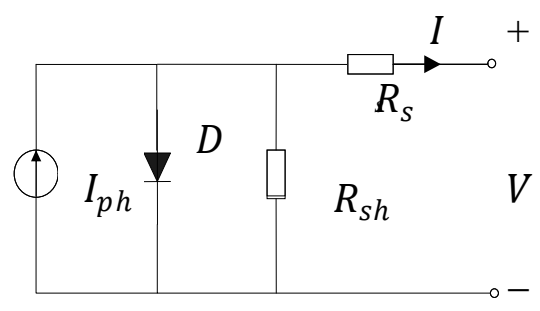

Fig 4: Mathematic model of a PV cell

The mathematic relationship for the current and voltage can be described as:

$$
I=I_{p h}-I_{s}\left(e^{\frac{q\left(V+I R_{S}\right)}{A k T}}-1\right) \frac{V-I R_{s}}{R_{s h}}
$$

where, $I_{p h}$ is photocurrent; $I_{s}$ is diode saturation current; $q$ is coulomb constant $\left(1.602 \mathrm{e}^{-19} C\right) ; k$ is Boltzman's constant (1.381e-23 J/K); $(T)$ is cell temperature $(K)$; $A$ is $P$ - $N$ junction ideality factor; $R_{S}$ and $R_{S h}$ are intrinsic series resistances.
Photocurrent is the function of solar radiation and cell temperature described as:

$I_{p h}=\left[\frac{S}{S_{r e f}}\right]\left[I_{p h, r f}+C_{T}\left(T-T_{r e f}\right)\right]$

where, $S$ is the real solar radiation $\left(\mathrm{W} / \mathrm{m}^{2}\right) ; \mathrm{S}_{\mathrm{ref}}, \mathrm{T}_{\mathrm{ref}}, \mathrm{I}_{\mathrm{ph}, \mathrm{rf}}$ is the solar radiation, cell absolute temperature, photocurrent in standard test conditions respectively; $\mathrm{C}_{\mathrm{T}}$ is the temperature coefficient $(A / K)$.

Diode saturation current varies with the cell temperature

$I_{s}=I_{s, r e f}\left[\frac{T}{T_{r e f}}\right]^{3} e^{\left[\frac{q E g}{A k}\left[\frac{1}{T_{r e f}}-\frac{1}{T}\right]\right]}$

where, $I_{s, r e f}$ is the diode saturation current in standard test conditions; $E_{g}$ is the band-gap energy of the cell semiconducteur $(\mathrm{eV})$, depending on the cell material.

When PV cells are arranged together in series and parallel to form arrays these cells are usually considered to have the same characteristics. The equivalent circuit of PV array can be described as figure 5 .

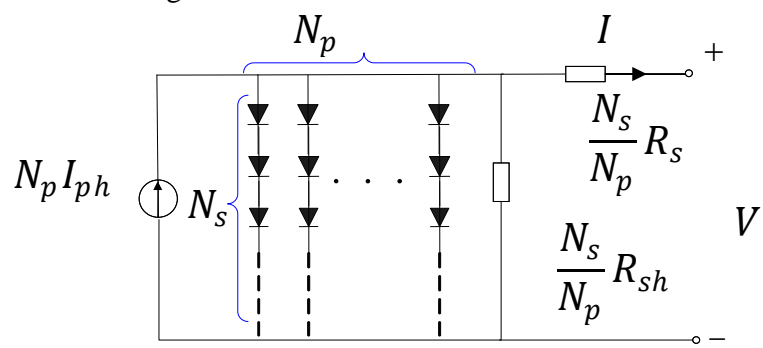

Fig 5: Mathematic model of a PV array

The relationship of the voltage and current in PV array is:

$$
I=N_{p} I_{p h}-N_{p} I_{S}\left(e^{\frac{q}{A k T}\left(\frac{V}{N_{S}}+\frac{I R_{S}}{N_{p}}\right)}-1\right) \frac{N_{p}}{R_{S h}}\left(\frac{V}{N_{S}}+\frac{I R_{S}}{N_{p}}\right)
$$

where, $\mathrm{N}_{\mathrm{s}}$ and $N_{p}$ are cell numbers of the series and parallel cells respectively.

We have used the software MATLAB/Simulink to implement the model of PV array, shown in figure 6. All parameters of the model use the data in table 1 .

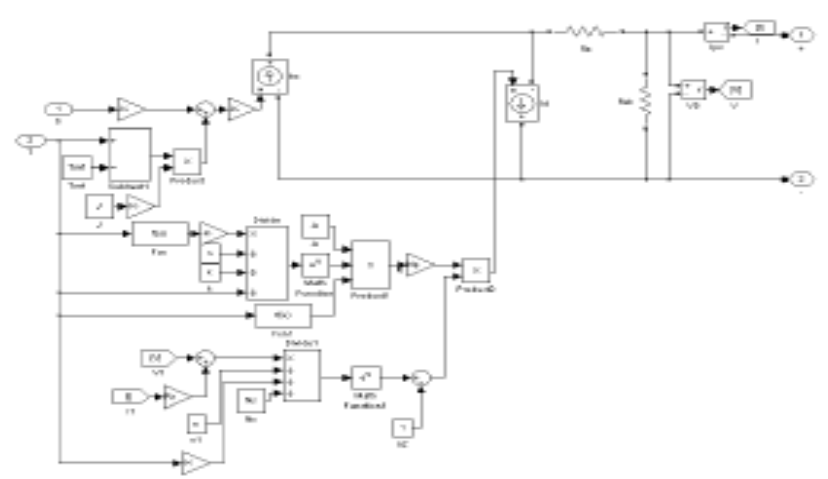

Fig 6: The model of PV array in MATLAB/Simulink 
Table 1. Parameters for PV model

\begin{tabular}{|c|c|}
\hline Parameters & Values \\
\hline Referenced solar irradiance $S_{r e f}$ & $1000 \mathrm{~W} / \mathrm{m}^{2}$ \\
Referenced cell temperature $T_{r e f}$ & $298 \mathrm{~K}$ \\
Cell numbers of a PV module $m$ & 36 \\
Parallel numbers of the PV modules $N_{P}$ & 9 \\
Series numbers of the PV modules $N_{S}$ & 20 \\
Photocurrent at standard condition $I_{p h, r e f}$ & $3.35 \mathrm{~A}$ \\
Band-gap energy $E_{g}(\mathrm{eV})$ & $1.237 \mathrm{eV}$ \\
Cell internal resistance $R_{s}$ & $0.312 \Omega$ \\
$P-N$ junction ideality factor $A$ & 54 \\
Temperature coefficient $C_{T}$ & $0.065 \%$ \\
& \\
\hline
\end{tabular}

With different temperatures and solar radiations, output characteristics of PV array are simulated as figure 7 and figure 8 .

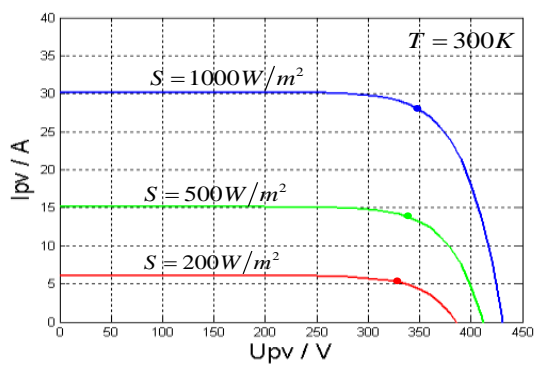

Fig 7: Characteristic curves of the PV array with different solar irradiations.

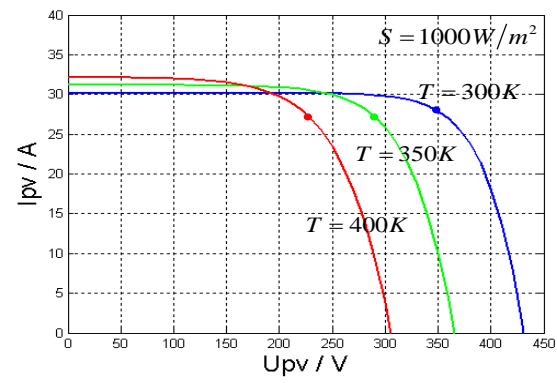

Fig 8: Characteristic curves of the PV array with different cell temperatures

\section{BATTERY MODEL}

The battery model [9] is based on a lead-acid battery one. The lead-acid battery cells consist of two plates, positive and negative immersed in a dilute sulfuric acid solution. The positive plate, or anode, is made of lead dioxide $\left(\mathrm{PbO}_{2}\right)$ and the negative plate, or cathode, is made of lead $(\mathrm{Pb})$. There a are two operating modes: the battery is in charge mode when the current into the battery is positive, and is in discharge mode when the current is negative.

The terminal voltage of the battery is given by:

$$
V_{b a t}=V_{1}+I_{b a t} * R_{1}
$$

Where $V_{1}$ and $R_{1}$ are deduced by a different set of equations depending on which mode of operation the battery is in. Values for the battery current $\left(I_{b a t}\right)$ are positive when the battery is in charge mode and negative when the battery is in discharge mode.

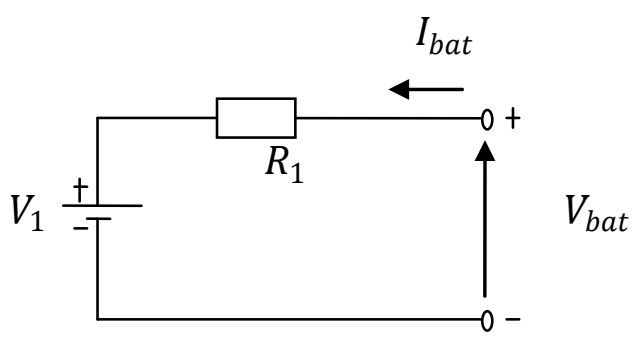

Fig 9: Battery model

\subsection{Charge Mode}

The battery charge and discharge equations are derived from those of Tyson H. [9]:

$V_{1}=V_{c h}=[2+0.148 * \operatorname{SOC}(t)] * n s$

Where: $S O C(\mathrm{t})$ is the current state of charge (\%) and $n s$ is the number of battery cells connected in series.

$$
\begin{gathered}
R_{1}=R c h=(0.758+(0.1309) /[1.06-S O C(t)] \\
* n s) / S O C m
\end{gathered}
$$

$V_{1}$ is the battery voltage; $V_{c h}$ and $R_{c h}$ are respectively the charging voltage across the battery and its internal resistance.

\subsection{Discharge Mode}

$$
\begin{gathered}
V_{1}=V_{d c h}=[1.926+0.124 * \operatorname{SOC}(t)] * n s \\
R_{1}=R_{d c h}=\left(\begin{array}{c}
0.19+(0.1037) /[\operatorname{SOC}(t)-0.14] \\
* n s) / S O C m
\end{array}\right.
\end{gathered}
$$

The most difficult part of the battery model is to accurately estimate the value of SOC $(\mathrm{t})$.

The estimation from the PSpice model [9] is described by the following equation:

$$
\begin{gathered}
\operatorname{SOC}(t+d t)=\operatorname{SOC}(t) *\left[1-E * \frac{d t}{3600}\right]+k * \\
{\left[V_{b a t} * I_{b a t}-R 1 * I_{b a t}{ }^{2}\right] * \frac{d t}{3600}}
\end{gathered}
$$

The equation (9) can be further simplified by substituting $V_{b a t}$ as a function of $V_{1}$ :

$$
\begin{gathered}
\operatorname{SOC}(t+d t)=\operatorname{SOC}(t) *[1-E * d t / 60]+[k * V 1 \\
* I b a t] * d t / 60
\end{gathered}
$$

It is necessary to use integration to solve for $\mathrm{SOC}(\mathrm{t})$ :

$$
\begin{gathered}
\operatorname{SOC}(t)=\operatorname{SOC}(t-1)+\int_{t-1}^{t} \frac{\left(k * V 1 * I_{b a t}\right)}{60 * S O C m} \\
-\frac{S O C(t-1) * E}{60} d t
\end{gathered}
$$


Where $\mathrm{t}$ is the time, $\mathrm{E}$ is the battery charge/discharge efficiency coefficient. Therefore, SOC (t) can be found if the previous condition is known. We assume known $\mathrm{SOC}(\mathrm{O})=\mathrm{SOC}(1)(\%)$ indicating available initial charge [9]. By looping the result with simulink, SOC $(t)$ can be found for any t. Figure 10 shows the lead-acid battery bank subsystem model with the MATLAB/simulink software. The only input to this subsystem is $\left(I_{b a t}\right)$ and the outputs of the system are battery voltage $\left(V_{b a t}\right)$, battery power $\left(P_{b a t}\right)$ and state of charge (SOC).

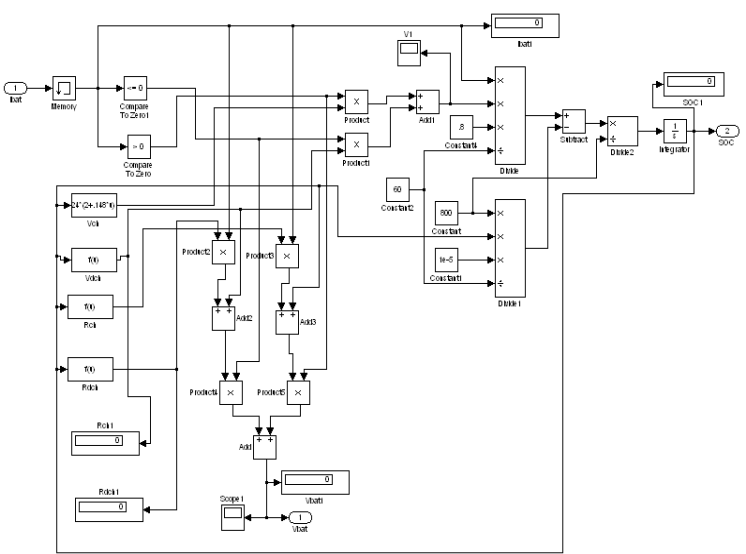

Figure 10: The battery model in MATLAB/Simulink

\section{DESCRIPTION OF THE PROPOSED TECHNIQUE}

The MPPT strategy proposed here consists of a combination of a neural network and $\mathrm{P} \& \mathrm{O}$ techniques for the implementation of the duty cycle regulator. When solar radiation changes slowly, the system controls the DC-DC converter using the $\mathrm{P} \& \mathrm{O}$, and the neural network learns simultaneously the MPP found by the P\&O. However if the solar radiation varies too rapidly, the neural network controller tracks the MPP rapidly and adjusts the duty cycle of the DC-DC converter.

Neural networks usually require independent and identically distributed samples to ensure successful on-line learning. Here, however, similar training samples are used by the artificial neural network (ANN). To deal with these training samples, we have used an MLP [7]-[8] with the help of Matlab neural networks toolbox in order to ensure fast and correct learning. The main idea is that the neural network learns each sample online because it is difficult to store all learning samples in small devices. The ANN learning technique is a memory-based one and allows to estimate at any instant the required optimal duty cycle 'D'. Even with sparse data in a multidimensional measurement space, the algorithm provides smooth transitions from one estimated value of D to another. The ANN consists of an input layer $\left(\mathbf{P}_{\text {pv }}\right)$, a pattern layer, a summation layer, and an output layer. The output $\mathrm{D}(\mathrm{x})$ of the ANN is as follow:

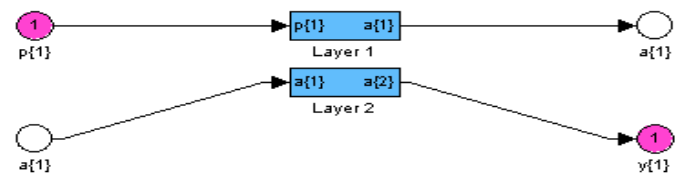

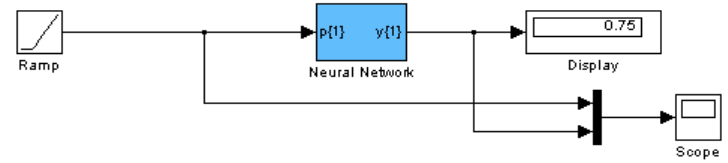

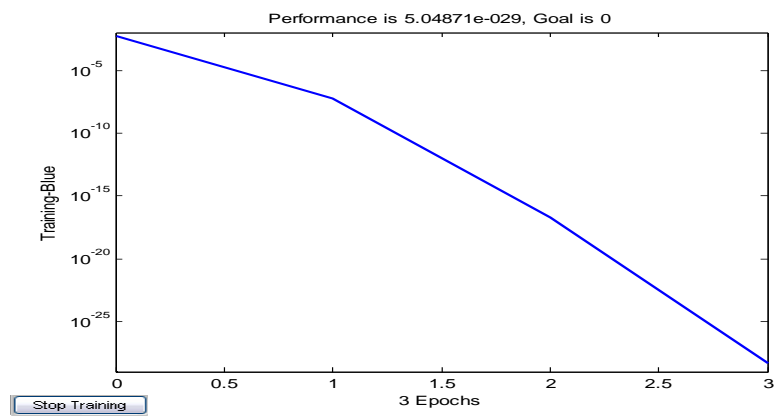

Fig 11: the ANN training error

During the learning stage of the ANN, the back-propagation training error is very small and is about $10.0 \mathrm{e}^{-25}$.

\section{THE OPTIMAL DUTY CYCLE DETRMINATION}

The MPPT technique proposed differs from other strategies [8], [9] and [10] in that the duty cycle of the switching of the DC/DC buck converter is optimally calculated on-line. The algorithm of the three-point weights comparison is run periodically by perturbing the solar array terminal voltage and comparing the PV output power on three points of the V-P curve. The three points are the current operation point (A), a point, $\mathrm{B}$, perturbed from point $\mathrm{A}$, and a point $\mathrm{C}$, with doubly perturbed in the opposite direction from point B. Figure 12 depicts the three possible cases. In these cases, for the points $\mathrm{A}$ and $\mathrm{B}$, if the power corresponding to the point $\mathrm{B}$ is greater than or equal to that of point $\mathrm{A}$, the status is assigned a positive weighting. Otherwise, the status is assigned a negative weighting. Amongst the three measured points, if two are positively weighted, the duty cycle of the converter should be increased. On the contrary, when two are negatively weighted, the duty cycle of the converter should be decreased. In the other cases with one positive and one negative weighting, the MPP is reached or the solar radiation has changed rapidly and the duty cycle is not to be changed. Figure 12 shows the idea of the MPP detection algorithm.

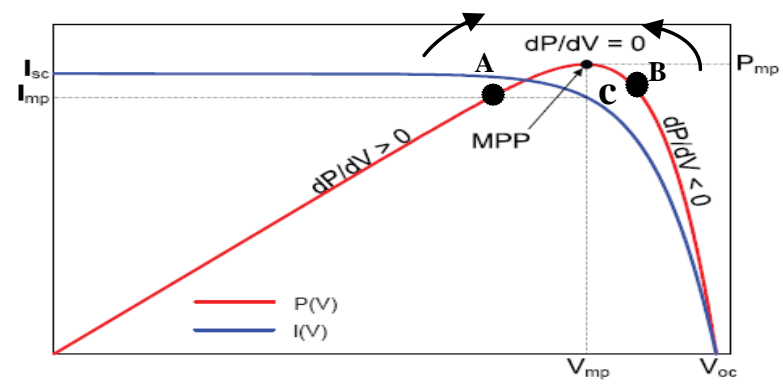

Figure 12: Sign of $\mathrm{dP} / \mathrm{dV}$ at different system operation positions By monitoring voltage $\mathrm{V}$ and current $\mathrm{I}$, the $\mathrm{P} \& \mathrm{O}$ algorithm determines whether generated power has increased. If so, the next change in voltage should be the same as the last $\mathrm{V}$. If not, the next change in voltage should be negative $\mathrm{P} \& \mathrm{O}$ achieves 
the function of an MPPT [8] easily, but it cannot track MPP rapidly when solar radiation changes quickly. In order to eliminate this drawback, this MPP technique utilizes an ANN to achieve on-line bus parameters learning and maximum power point tracking. The MPP tracker operates by periodically incrementing or decrementing the estimated solar panel voltage Vpv. If a perturbation occurs on the PV output, then the subsequent perturbation is generated in the opposite direction. Figure 12 presents the simulation program using MATLAB/Simulink. The weights of the neurons are changed subsequently to the presence and severity of a perturbation. They are maintained constants in stable working conditions.

\section{SIMULATION RESULTS AND DISCUSSION}

Figure 13 shows the overall simulation circuit under MATLAB/Simulink In order to validate the on-line learning ANN, many simulations tests have been implemented.

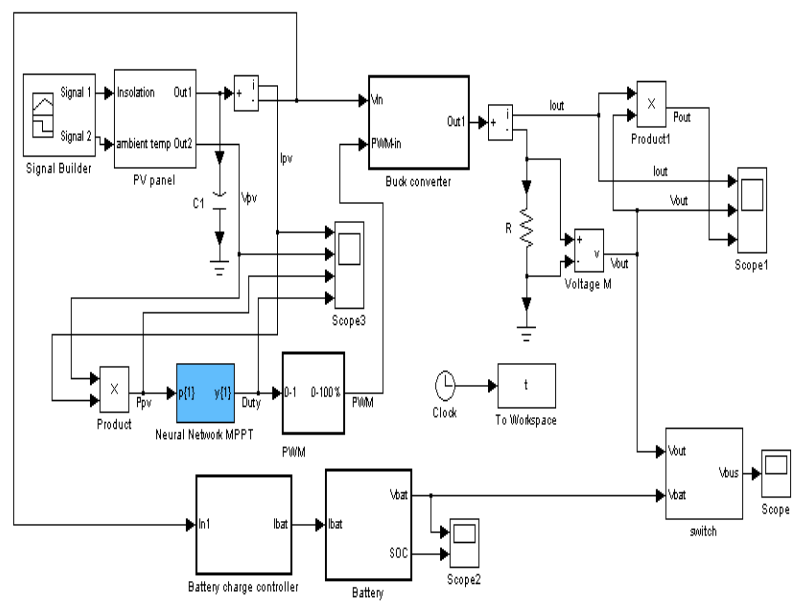

Fig13: Simulation system of the Online Learning Neural Networks

Based on the above model and control methods, the gridconnected hybrid PV/Battery generation system can be implemented using the MATLAB/Simulink, as shown in figure 13. In our work, three operation cases are studied, namely:

a. Operation simulation without presence of disturbances.

b. Operation simulation with disturbances presence.

c. Operation simulation of the PV system with step changes of solar irradiance.

\section{6.a Simulation of the system operation without disturbances}

During normal operation, the solar irradfiance is considered to be $900 \mathrm{~W} / \mathrm{m}^{2}$, and the ambient temperature is $47^{\circ} \mathrm{C}$ [7].

The total simulation time is taken 0.1s [8]. At the start, the system undergoes a short transietnt period of about $20 \mathrm{~ms}$. It can be noticed in figures 14(a)-(b)-(c) that without the presence of disturbances, the PV panel ouput voltage, current and power present high amplitude oscillations during this period. The MPP tracking control garantees maximum output bus power of $400 \mathrm{~W}$ and the duty cycle $\mathrm{D}$ witch the main control parameter of the DC-DC buck converter varies between 1 at the start then decreases to a steady value of 0.75 . Figures 14 (d)-(e)-(f) show respectively the bus voltage, the load current and the dc-dc buck converter output power witch feeds a load (a resistance ) of $6.5 \Omega$.

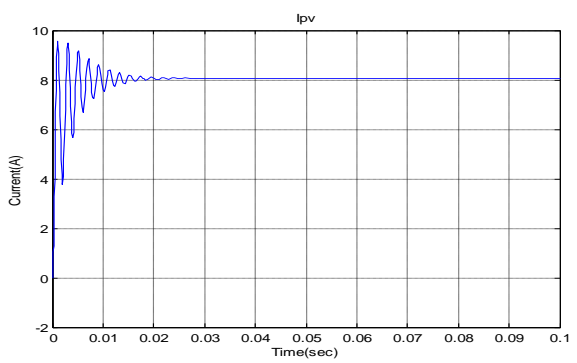

Fig 14 (a): The output PV panel current

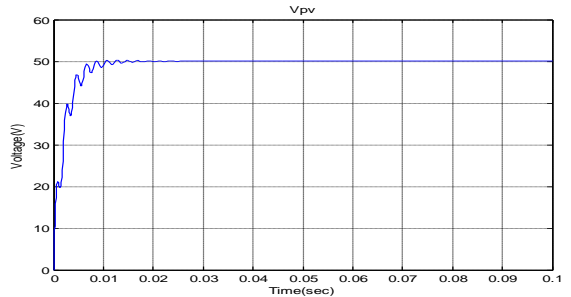

Fig14 (b): The output PV panel voltage

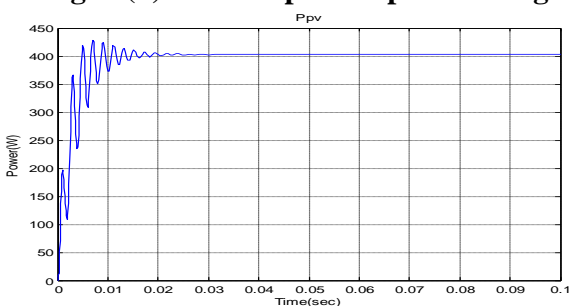

Fig14 (c): The output PV panel power

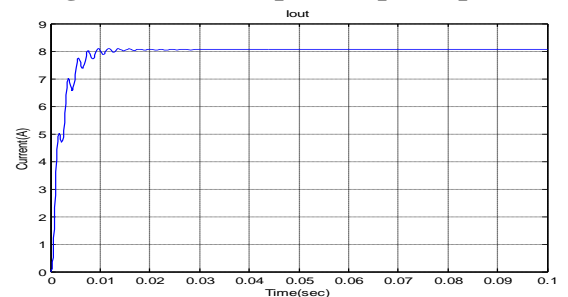

Fig14 (d): The Buck converter output current

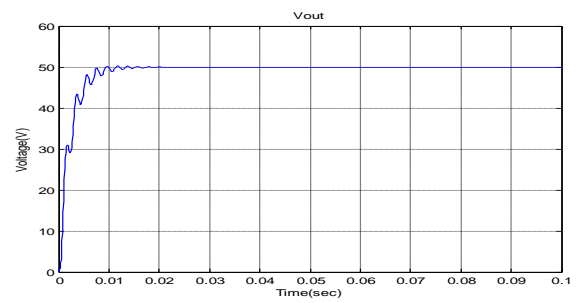

Fig14 (e): The Buck converter output voltage

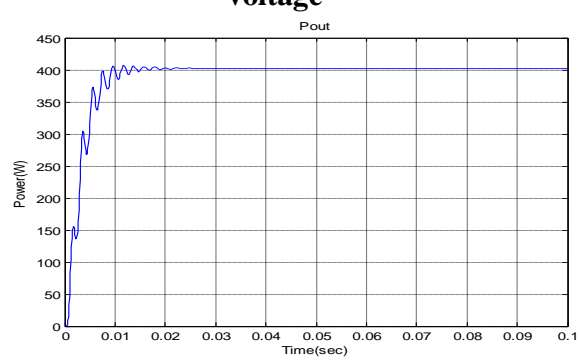

Fig14 (f): The Buck converter output power 


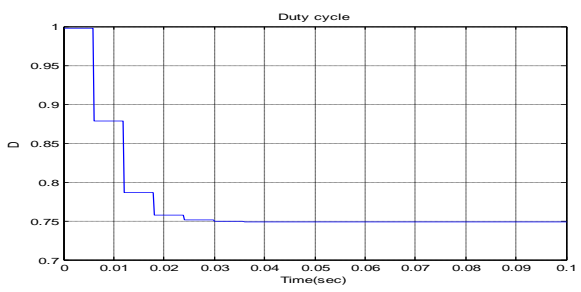

Fig14 (g): The variation of the dc-dc Converter duty cycle

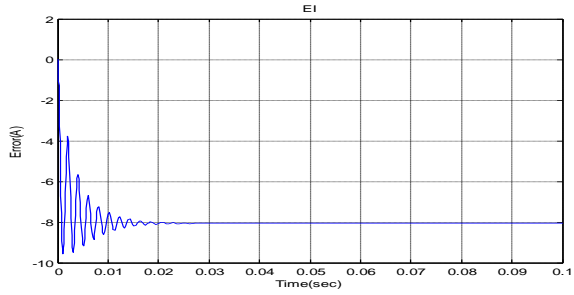

Fig14 (h) : variation of the error current

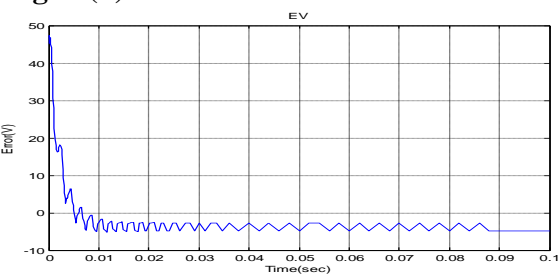

Fig14 (i) : variation of the error voltage

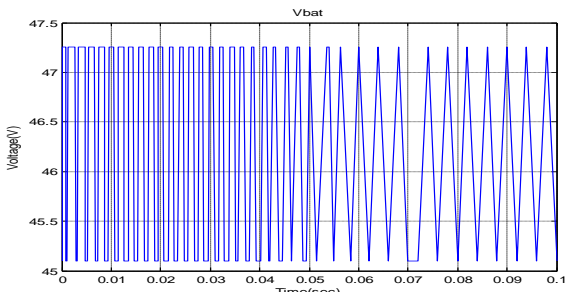

Fig14 (j): The output battery voltage

Figures 14 (h)-(i) show respectively the errors of the currents, and the voltages and figure 14 (j) depicts the variations of the voltage across the battery under normal condictions, ie without disturbances.

\section{6.b Simulation of the PV operation with disturbances occurance}

In Figures 14(a1)-(b1)-(c1)---((k1) two different distrubances are assumed as input in the irradiance of PV panel (using signal builder bloc of simulink). The first one 'd1' correponds to a sudden step increase of $100 \mathrm{w} / \mathrm{m} 2$ in the irradiance wich occurs at $0.3 \mathrm{~s}$ and the second one ' $\mathrm{d} 2$ ' is a sudden step decrease of $100 \mathrm{w} / \mathrm{m} 2$ wich happens at $0.8 \mathrm{~s}$. The ANN controller adjusts the duty cycle of the dc-dc buck converter to produce maximùum power to charge the battery that is shown in figure $14(\mathrm{~g} 1)$.

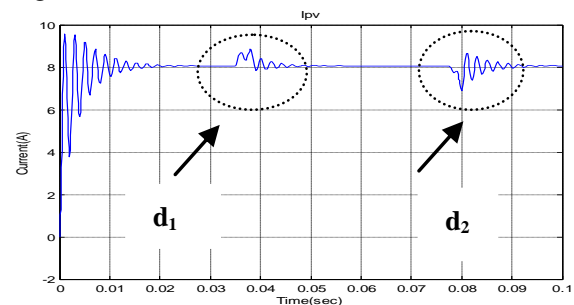

Fig14 (a1): The output PV panel current with disturbance

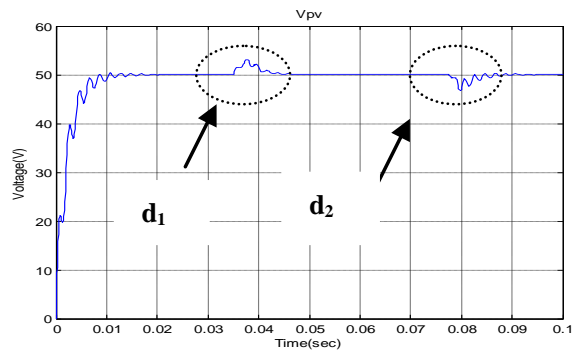

Fig 14 (b1) : The output PV panel voltage with disturbance

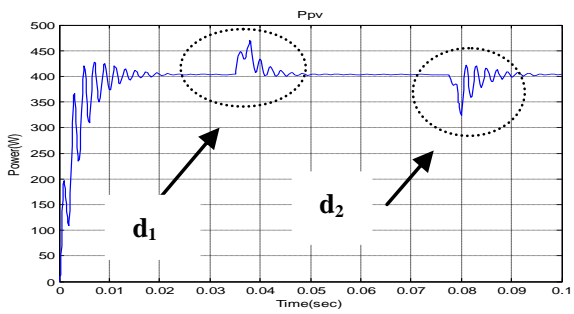

Fig 14 (c1) : The output PV panel power with disturbance

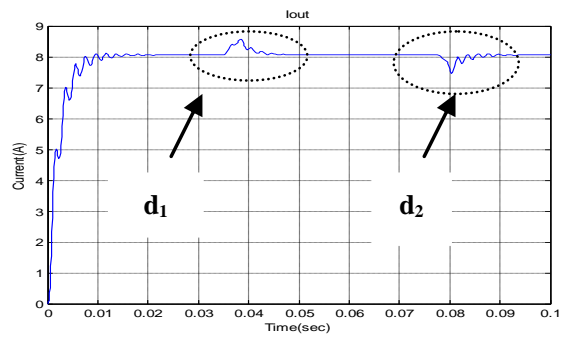

Fig 14 (d1): The Buck converter output current with disturbance

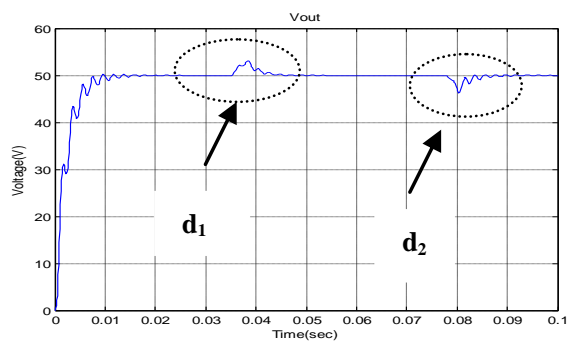

Fig 14 (e1): The Buck converter output voltage with disturbance

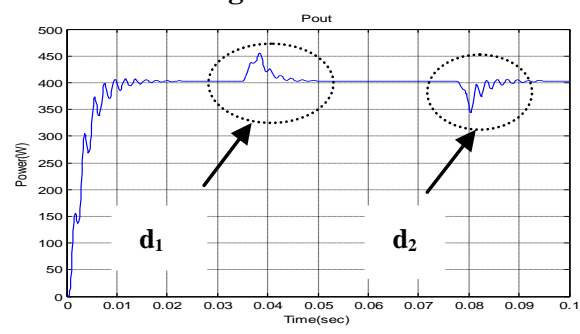

Fig 14 (f1): The Buck converter output power with disturbance

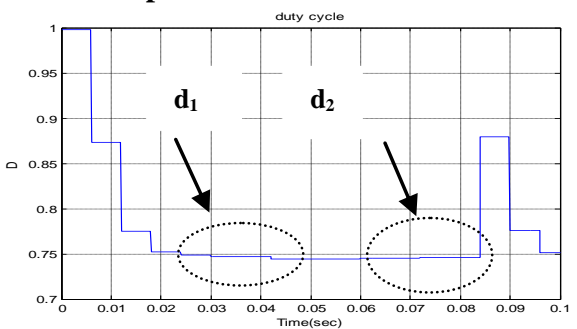

Fig 14 (g1) : Variation of the duty cycle 


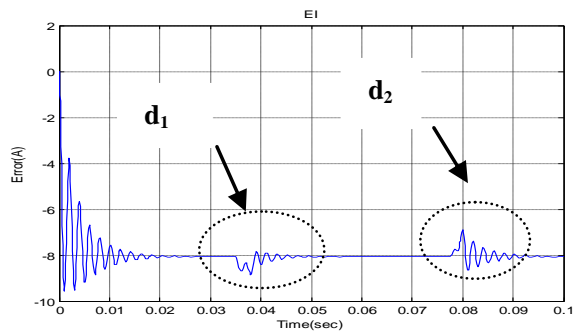

Fig 14(h1): The error current with disturbance

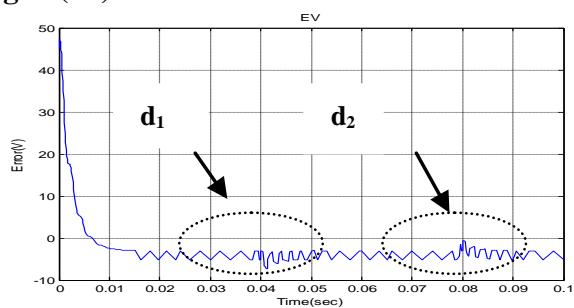

Fig 14 (i1):The error voltage with disturbance

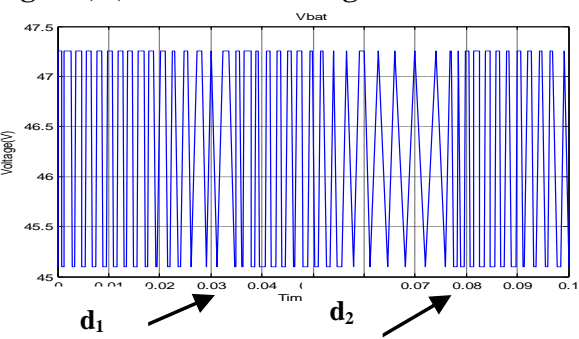

Fig 14 (j1): The output battery voltage with disturbance

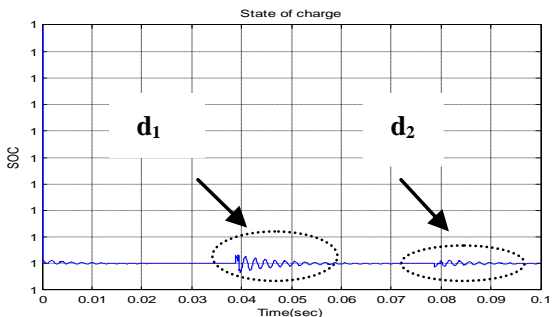

Fig 14 (k1): The State of charge (SOC) of the battery

The figures above mentionned show that the MPP control tracks the charging and dischanging of the back-up battery quickly when the shading of the PV panel changes considerably [6] and quickly, and has high control precision and stability in charging and discharging from the state of charge of the battery (Figure 14 (j1)). According to the noticed difference in the simulation results obtained by [ [1][6]-[7]-[8]-[10] and [11], that the output PV panel (Fig. 14(c1)) and the bus converter output power (Fig. 14(d1)) to the utility load the efficiency of the photovoltaic battery charger is high and the figure 14 (g1) depicts the variation of the duty cycle $\mathrm{D}$ of the buck converter instantly with the disturbance and its corrrection on-line relatively to the nature of the disturbance.

\section{6.c Simulation with step changes of solar irradiance}

Moreover, in order to prove the efficiency of the ANN-MPPT on-line controller, we have simulated in figure 14(a2)-(b2)--(h2) a continuous step increase of solar irradiance. The ANN controller shows that it tracks the maximum power point reliably, in order to avoid having to move rapidly the operation point, when the solar radiation is varying quickly or when a disturbance or data reading error occur.

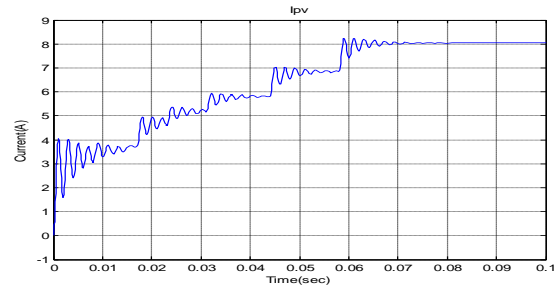

Fig 14 (a2): The output PV panel current with a step change of irradiance

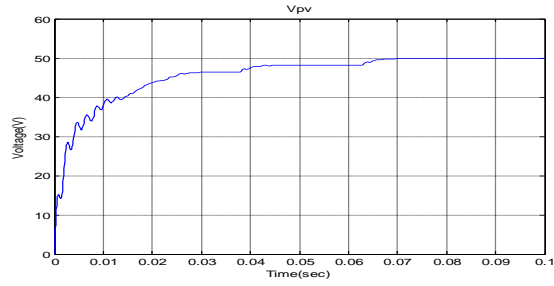

Fig 14 (b2): The output PV panel voltage with a step change of irradiance

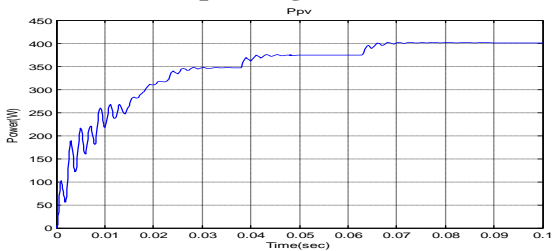

Fig 14 (c2): The output PV panel power with a step change of irradiance

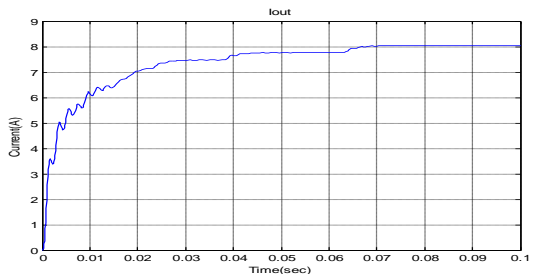

Fig 14(d2) : The Buck converter output current with a step change of irradiance

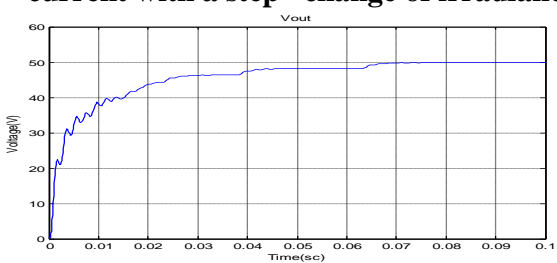

Fig 14(e2): The Buck converter output voltage with a step change of irradiance

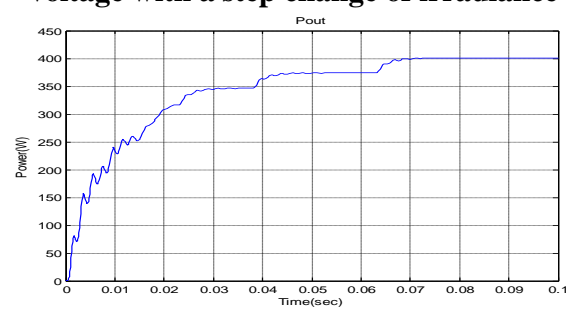

Fig 14(f2): The Buck converter output power with a step change of irradiance 


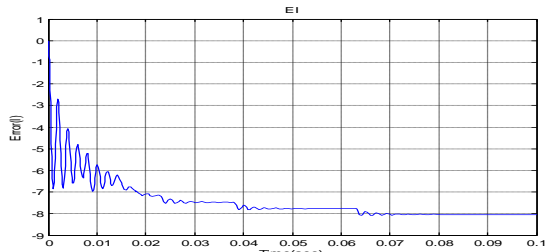

Fig14 (g2): Error current with a step change of irradiance

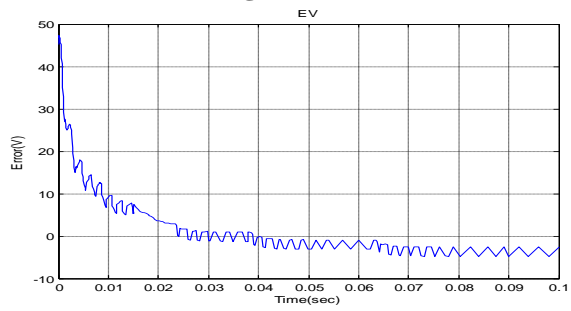

Fig 14 (h2): Error voltage with a step change of irradiance

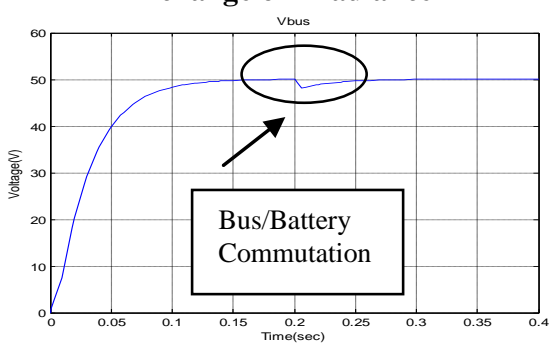

Fig14 (a3): the output voltage bus during voltage drop.

Figure 14 (a3) shows the commutation between the battery and the bus [12], when the PV voltage suddenly drops, a swith logic inserted acts to reestablish the bus voltage to the required level of $50 \mathrm{~V}$ which feeds a load.

\section{CONCLUSION}

An on-line ANN controller, in conjuncion with the wellknown $\mathrm{P} \& \mathrm{O}$ technique [7], and using the back-propagation algorithm in order to minimize the controlled error, has been utilized for online estimation of the reference voltage in the feed-forward loop. The simulated results using the on-line training of the ANN show that the efficiency of the MPPT and the effectiveness of this control method is higher than the classical one. This stratgy has several advantages, particularly in that there is no need for voltage and current sensors, and in that it avoids a complex calculation of power. Finally, the maximum output power of photovoltaic battery is insured under sudden shading conditions [6] of the PV panel and there is continuous impedance matching of the PV source and the system battery-load. Other hybrid techniques using the PSO and a ANN could be used for further enhancement of the MPP tracking of stand-alone PV systems.

\section{REFERENCES}

[1] S. Gomathy, S. Saravanan, and Dr. S. Thangavel, "Design and Implementation of Maximum Power Point Tracking (MPPT) Algorithm for a Standalone PV System", International Journal of Scientific \& Engineering Research, Vol. 3, N³, 2012.

[2] L. Fangrui, Y. Kang, Y. Zhang, and S. Duan, "Comparison of P\&O and Hill Climbing MPPT Methods for Grid-Connected PV Converter," Industrial Electronics and Applications, 2008, ICIEA 2008. 3rd IEEE Conference on. pp. 804-7. 2008

[3] O. Lopez Lapena, M. Penella, and M. Gasulla, "A new MPPT method for low-power solar energy harvesting," IEEE Trans. Ind. Electron., Vol. 57, N ${ }^{\circ}$, pp. 31293138, Sep. 2010.

[4] L.Piegari and R. Rizzo, "Adaptive perturb and observe algorithm for photovoltaic maximum power point tracking," IET Renewable. Power Gen., Vol. 4, N . 4, pp. 317-328, Jul. 2010.

[5] M. Makhlouf, F.Messai, and H. Benalla, "Modeling and Simulation of Grid-connected Hybrid Photovoltaique Battery Distributed Generation System". Canadian Journal on Electrical and electronics Engineering Vol, 3, $\mathrm{N}^{\circ} 1,2012$.

[6] N. Boutasseta, "PSO-PI based Control of Photovoltaic Arrays International Journal of Computer Applications, Vol. 48, N¹7, pp. 36-40, June 2012.

[7] D. Vasarevicius1, R. Martavicius1, and M. Pikutis1, "Application of Artificial Neural Networks for Maximum Power Point Tracking of Photovoltaic Panels"Elektronika ir Elektrotechnika, ISSN 1392-1215, Vol. 18, $\mathrm{N}^{\circ}$ 10, 2012.

[8] Chun-hua Li, Xin-jian Zhu, Guang-yi Cao,Wan-qi Hu, Sheng Sui,Ming-ruo Hu, "A Maximum Power Point Tracker for Photovoltaic Energy Systems Based on Fuzzy Neural Networks", "Journal of Zhejiang University Science A", Vol. 10, N. 2, pp. 263-270, 2009.

[9] Tyson D, "Design and simulation of photovoltaic super system using simulink",Project of Electrical Engineering, Calfornia Polytechnic State University,San LuisObispo, 2006.

[10] Uwe Zimmermann, and Marika Edoff,"A Maximum Power Point Tracker for Long-Term Logging of PV Module Performance" IEEE Journal of Photovoltaics, Vol.. 2, $\mathrm{N}^{\circ} .1,2012$.

[11] K. Kassmi, M. Hamdaoui et F. Olivié "Conception et modélisation d'un système photovoltaïque adapté par une commande MPPT analogique", Revue des Energies Renouvelables, Vol. 10, N4, pp. 451 - 462, 2007.

[12] Sree Manju B, Ramaprabha R ,and Mathur B.L, "Design and Modeling of Standalone Solar Photovoltaic Charging System" ,International Journal of Computer Applications, pp.41-45, Vol 18- No.2, March 2011. 